\title{
Influence and Strategies of Liaoning Dialect on English Teaching
}

\author{
Jie Fu \\ College of Foreign Languages, Bohai University, Jinzhou, 121013, China
}

563714244@qq.com

Keywords: Liaoning dialect; English language teaching; influence; strategy; negative transfer of mother tongue

\begin{abstract}
Dialect and culture have inseparable close contact, dialect format and also form culture at the same time in this area. On the one hand, the cultivation of English language is slow and requires the process of finishing the "three-language interaction conversion". On the other hand, the localization of language thinking is the language thinking based on the regional dialect. In order to eliminate the influence of dialect on English teaching, the teaching strategies put forward are as follows: cultivating cross-cultural communication ability, promoting the use of situational teaching methods, English and dialect speech synchronization training, organizing classroom teaching in English, eliminate dialect interference strengthen English thinking, vigorously promote the campus Putonghua.
\end{abstract}

\section{Introduction}

Language is an important part of culture and an aspect of culture. People understand the world through language, use language for social communication, express their mind, organize production activities, and transmit knowledge. Language is the carrier of culture, reflecting the culture of a nation. Language carries rich cultural information, reflecting the nation's historical and cultural background, as well as people's thinking patterns, social behavior and way of life. Language and culture mutual influence, mutual restraint. With the continuous development of society, the language of speech, vocabulary, discourse structure and rhetorical principles will have an impact. When thinking develop to a certain extent, language forms can not meet the needs, it will promote the language changes, language content is more abundant, culture continues to develop. In foreign language teaching, we should cultivate students' cultural sensitivity and consciousness as an important task, and then improve the ability of intercultural communication.

Dialect is the variant of language, according to the nature of dialects can be divided into regional dialects and social dialect. The regional dialect is the variation of the language due to the regional differences, which is the reflection of the imbalance of language development. The social dialect is the social member of the same area because of the differences in occupation, class, age, gender and cultural upbringing, and the formation of different social variants. Dialect and culture have an inseparable close contact, on the one hand, dialect is the carrier of culture, between different people through dialect communication also realized the cultural exchange and integration. On the other hand, dialect in a certain regional common use, not only a social phenomenon, but also a cultural phenomenon. Reflecting the foundation and essence of national culture. Dialect formed at the same time also formed culture in this area. Dialect and the culture of this region in the formation and development of the process of mutual promotion. Reflecting the national culture, while the dialect reflects the regional culture. Dialect and culture are inextricably linked.

From the historical point of view, the Liaoning dialect vocabulary mixed with the history of Manchu, Mongolian and other languages of some vocabularies, southern Liaoning region also absorb foreign words such as Japan and South Korea. Liaoning dialect within the strong consistency and little difference. In this paper, according to the characteristics of Liaoning dialect, this paper analyzes the influence of Liaoning dialect on English teaching, and then puts forward the corresponding strategies to improve the teaching of English and cultivate students' intercultural 
communicative competence.

\section{Negative Transfer of Mother Tongue and Learning English}

Transferring, from a psychological term refers to the effect of learning on another learning, or the experience that has been acquired, the effects of other activities. Language transfer refers to the influence of similar or differences between previously acquired language and target language. And is divided into positive and negative transfer, the former is when some characteristics of mother tongue have the same or similar words, play a positive role in promoting; the latter is the mother tongue and the target language have a certain difference, with some of the rules of the mother tongue resulting in negative transfer, hinder the target language learning. English teaching in China is a foreign language teaching, students learn English, has been using the mother tongue communication, so very familiar with the use of native language rules. When you learn English, you will not consciously apply the rules of native language to English, so there are many errors, that is, the negative transfer of mother tongue.

In the process of foreign language learning, when there is a communicative intention, will try to use the target language of the pragmatic rules, because in this area too little knowledge, will naturally resort to the mother tongue of the pragmatic rules or by the mother tongue of the development of intermediaries language rules, resulting in the intention of communication to the other party to be changed. Similarly, in the acceptance of information, there is a similar situation, failed to follow the target language of the pragmatic rules to understand the transmission of the target language information, and with their own mother tongue pragmatic rules to understand, will misunderstand each other with mistakes. These two processes are shown in Fig.1.

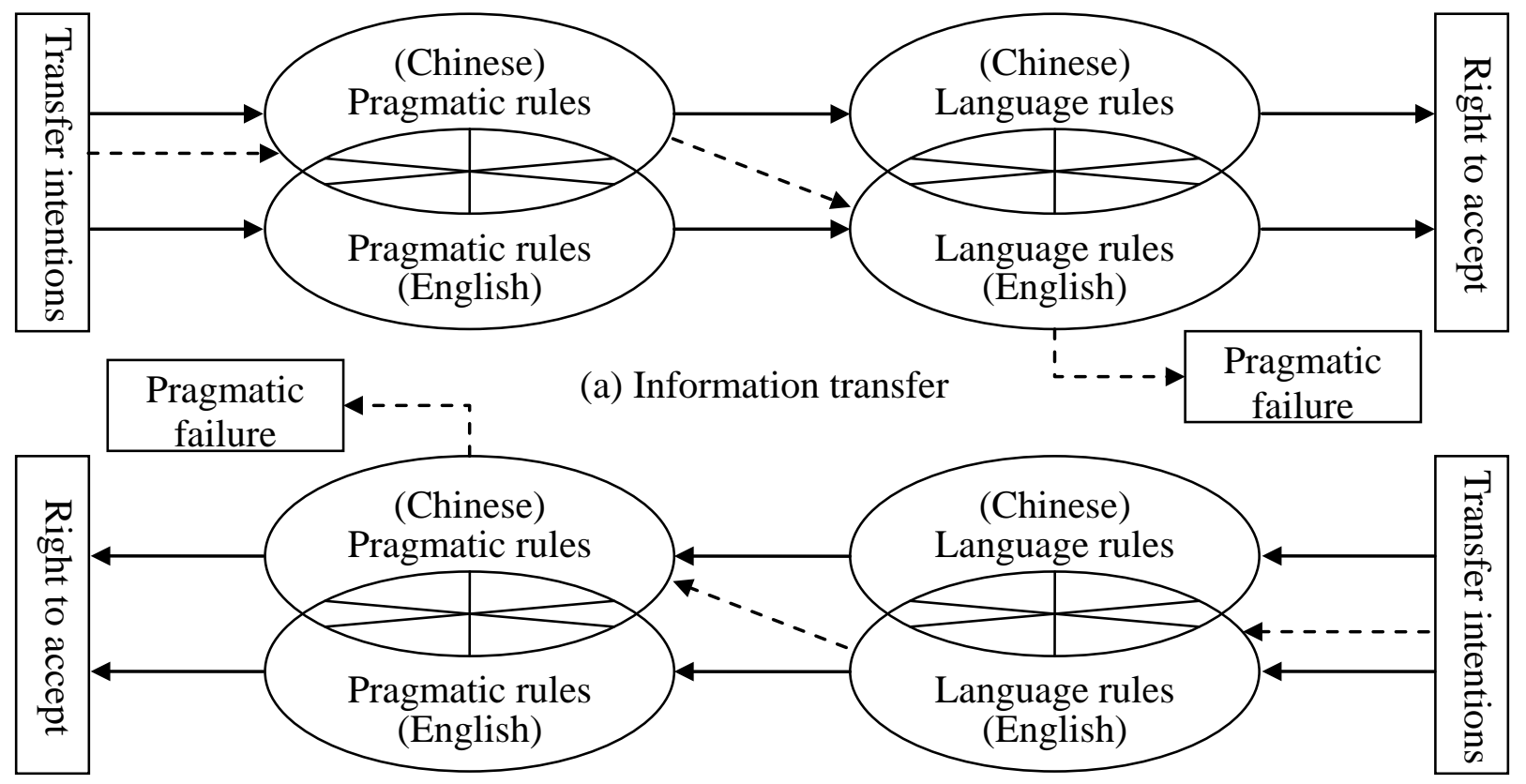

(b) Information received

Fig. 1. Process on information transfer and information received

In the process of English learning, the negative transfer of mother tongue is inevitable. In the process of English teaching, it should be based on the law of mother tongue migration, avoid weaknesses, give students the right guidance, and in the teaching to develop appropriate strategies, rational use of mother tongue is moving, the negative transfer control in the smallest range, improve learning efficiency and use English ability to communicate.

\section{Influence of Liaoning Dialect on English Teaching}

Liaoning dialect has an impact on English teaching, mainly in the following two aspects: 
(1) English language sense training is slow. Language sense is people in the long-term language practice and format the keen and rich sense of comprehension. Language sense is the language of the text analysis, understanding, experience and absorption of the whole process of high concentration. Language sense is a kind of experiencial colorful and strong ability, involves the study experience, life experience, psychological experience and emotional experience, including understanding ability, judgment ability and association ability and many other factors. In the process of English learning, students in the dialect area should carry out "two" thinking activities, and Putonghua becomes a bridge between dialect and English. When students need to speak in English, first turn the familiar dialect thinking into unfamiliar Putonghua, and then convert Putonghua into a completely strange English language; conversely, when students need to understand the English sentences, the eyes see the English sentence, the minds of English sentences are not familiar with the interpretation of Putonghua, and finally through the thinking of conversion, in order to use the most familiar language, that is, local dialects, the English sentence thoroughly understand. For the dialect students, whether it is to use English to express their own ideas, or to understand the English language in Chinese, have to go through the "three-language interactive conversion" processing and finishing process in the brain to carry out a series of language code conversion. This makes the formation of good English language sense in the teaching process becomes extremely slow.

(2) Language thinking is regional. Language is not only a tool of communication, but also a tool of thinking. Thinking activities, especially abstract thinking activities, must rely on language, can not leave the language alone. Language and thinking interdependence and common development. Thinking is inseparable from the language, language can not be separated from thinking. On the one hand, there is no language, thinking activities can not be carried out, thinking results can not express, thinking can not exist; the other hand, language as a tool of thinking, only in the course of thinking there is the use of meaning, if there is no thinking activities, communication and thought, language tools will lose the value of existence. So language and thinking are mutually reinforcing relationship, the two each with the other for the existence of conditions. Thinking must be based on the basis of language materials, where there are thinking activities, where there is language activities. The close relationship between language and thinking is also reflected in how much language and mind are adapted to each other, how high is the level of development of mind, and how much language development is. A kind of language, regardless of the structure is simple and complex, are able to meet the needs of a social group of communication, of course, can meet the requirements of thinking. Therefore, the human language is a product of society, for a certain social services. Dialect as an important part of the specific regional culture, embodies a region of the people of the basic understanding of the world, carrying people in the long history of the process of accumulation of a large number of cultural information, is composed of regional culture, one of the important elements. In this way, based on the regional dialect language thinking, there must be regional characteristics.

\section{Teaching Strategies to Eliminate the Influence of Liaoning Dialect on English}

Teaching strategy is to complete the task of teaching methods used to solve the teachers how to teach and how students learn, for the completion of teaching objectives, improve the quality of teaching and so on is of great significance. In view of the influence of Liaoning dialect on English teaching, the teaching strategy proposed in this paper is as follows:

(1) Cultivate cross-cultural communication skills. Intercultural communication is a kind of communicative behavior, from the kind of communication, can be interpersonal communication, can also be communication between individuals and groups. Economic globalization and the continuous development of information network, globalization has become an irreversible trend, from different geographical and cultural background of the people, increasingly formed the status of the world citizenship, cross-cultural communication ability to become people's basic survival skills. Cultivating students' intercultural communicative competence requires students to obtain a lot of cultural content, in addition to learning language knowledge, but also must contact the rich cultural 
connotation. Teachers should use effective teaching methods to penetrate the cultural elements in the teaching process, students take effective learning methods to actively absorb the British and American culture, and ultimately achieve cross-cultural communication ability to enhance the purpose. With the deepening of learning, foreign cultures and foreign languages, a large number of input, and after a long period of language and cultural output, learning ability continue to strengthen, from the mother tongue dialect interference and influence is bound to become increasingly weak.

(2) Promote the use of situational teaching methods. In the process of teaching, according to the basic principles of education and psychology, according to the different characteristics of students, through the establishment of teachers and students, cognitive objects and cognitive emotions between the emotional atmosphere, create suitable learning environment, so that Teaching is carried out in a positive emotion and an optimized environment, allowing learners' emotional activities to participate in cognitive activities, activating situational thinking, acquiring knowledge in situational thinking, developing competencies and developing intelligence. The situation teaching mode is different from the pedagogy and is different from the theory of teaching. It is based on the principles of pedagogy, epistemology, psychology and teaching theory. The non-intellectual factors are developed in cognitive activities so as to realize the basic teaching mode of cheerful teaching. Teachers are encouraged to take advantage of various means, including English movies and television, English newspapers and fiction, all kinds of excitement and hobbies, and actively participate in English corner, English contest and fun games, as well as various English translation activities, English environment and atmosphere, and gradually cultivate in the dialect context, both with dialect thinking and expression, but also in English thinking and expression, and constantly develop students positive emotions on English.

(3) English and dialect speech synchronization correction training. Different pronunciation systems have good adaptability and self-control, which is necessary to learn the language conditions. Practice has proved that the scientific voice pronunciation training, has strong compatibility and compatibility, the sound of the system after training has very positive impact and a wide range of adaptation. Speaking from the theory of language, voice and vocal resonance, the sound system has a strong ability to adapt and imitation, whether the pronunciation of the dialect mother tongue has a strong convincing force, and the day after the effective training is extremely important. Putonghua standard pronunciation, suitable for dialect pronunciation of the corrective function of the mother tongue, also applies to English teaching voice training. From the Putonghua and English standard sound two pronunciation system, for Liaoning dialect, develop to overcome the four questions of Putonghua, before and after the nasal problem, children and other problems of the correction program. Summed up the corresponding phrases and word groups, the daily expression of training, to overcome the long-term dialect mother tongue.

(4) Organize classroom teaching in English. The use of English teaching, classroom teachers in English to explain, students with English thinking; teachers ask English questions, and students answer in English. Minimal use of Chinese, should not use dialect to reduce the influence of dialect. The whole teaching has always been student-centered, consistent with English communication, "listening and speaking" integration, the implementation of the "listening, speaking, reading and writing" ability to cultivate the teaching principles. The purpose of English teaching is to cultivate students' ability to use English. This ability can only be cultivated by using English in a large amount of English and immersed in English. Organize teaching in English to better implement student-centered and communicative principles. There are three advantages in the organization of English teaching: first, it is conducive to cultivating students' English thinking ability, English explanation and English association are the process of cultivating students' direct English thinking ability. After all over time, there must be a qualitative leap; open up a new channel of learning, reducing the burden on students, cultivating students' "listening, speaking, reading and writing" ability; third, deepen the understanding and improve the memory effect.

(5) Eliminate dialect interference and strengthen English thinking. English thinking mode is mainly embodied in the word meaning and usage, syntax and grammar phenomenon. Specific words, syntax and grammatical phenomena contain English thinking mode, which is modeled into a 
learning mechanism to guide students to express their thoughts accurately. The difference between English thinking and Chinese thinking is mainly embodied in four aspects: first, Chinese is more intuitive, English tends to see the essence through the phenomenon; second, the Chinese is subjective, English is strong objective; third, in the sentence expression, Chinese start from the whole, first part is the whole, then the part, English is exactly the opposite; fourth, the English sentence structure is rigorous, Chinese is relatively loose. In the course of English teaching, when you encounter sentences with different ways of expressing English and Chinese, you should practice to achieve familiar purposes. When you introduce background knowledge, you should point out cultural differences.

(6) Vigorously promote the campus Putonghua. Putonghua is the universal language of the whole China. In the campus popular use Putonghua, you can improve the exchange effect, standardize teachers and students words and deeds, improve the awareness of teachers and students civilization, beautify the campus education environment. The school should incorporate the requirements of the students' language awareness and the application ability of Putonghua into the curriculum standards of the various disciplines, incorporate the basic contents of education and teaching, incorporate the school work schedule and routine management, and infiltrate into educational activities such as moral education, sports, aesthetic education and social practice , The teachers should put Putonghua teaching into the daily classroom teaching, in the classroom, teachers have the responsibility to students of Putonghua teaching. Good Putonghua can improve the cognitive ability of language. Schools at all levels should vigorously promote the campus Putonghua, teachers and students in the campus with Putonghua daily communication, narrowing the distance between dialect and Putonghua.

\section{Acknowledgment}

This work is supported by social science fund project of Liaoning province (L15BYY007): Phonetics Characteristics of Liaoning dialect and its influence on English education in Liaoning.

\section{References}

[1] N. Fu, "The analysis of the adverse effects of dialects on English learning and the ways to correct them: Take Tongren region as an example," Education Exploration, vol. 32, no. 3, pp. 66-67, 2012.

[2] Z. Xing, "Negative transfer of mother tongue in English learning," Journal of Language and Literature Studies, vol. 34, no. 1, pp. 130-131, 2014.

[3] Y. B. Ou, "On situational teaching method and its theoretical basis," Economic management, vol. 13, no. 9, pp. 52-52, 2016.

[4] Y. J. Wang, Y. L. Zhang, "Cross cultural communication and English teaching," Education Teaching Forum, vol. 9, no. 5, pp. 85-86, 2017.

[5] Q. Y. Zhang, "The influence of Liaoning Dialect on College Students' English learning," Crazy English (Teachers), vol. 4, no. 12, pp. 57-60, 2007.

[6] G. L. OuYang, "Summary on the Research of Liaoning Dialect in Past 60 Years," Huazhong Normal University Journal of Postgraduates, vol. 17, no. 4, pp. 50-52, 2010.

[7] J. Zhu, "Dialects and Foreign Language Learning: Questionnaire survey and analysis of Heyuan Polytechnic," Journal of Xinjiang University (Philosophy, Humanities \& Social Sciences), vol. 37, no. 6, pp. 148-150, 2009.

[8] XIA Rui, "The Strategies of College English Teaching in the Northwest Dialect Areas," Journal of Lanzhou Polytechnic College, vol. 19, no. 2, pp. 94-96, 2012. 